\section{OPEN ACCESS}

Edited by:

Rafael Luque,

Universidad de Córdoba, Spain

Reviewed by:

Regina De Fatima Peralta Muniz

Moreira,

Universidade Federal de Santa

Catarina, Brazi

Evangelos Topakas,

National Technical University of

Athens, Greece

*Correspondence:

Madalina Tudorache

madalina.sandulescu@g.unibuc.ro

Vasile I. Parvulescu

vasile.parvulescu@g.unibuc.ro

Specialty section:

This article was submitted to

Green and Sustainable Chemistry,

a section of the journal

Frontiers in Chemistry

Received: 14 December 2017 Accepted: 03 April 2018

Published: 20 April 2018

Citation:

Ion S, Opris C, Cojocaru B, Tudorache M, Zgura I, Galca AC, Bodescu AM, Enache M, Maria G-M and Parvulescu VI (2018) One-Pot

Enzymatic Production of

Lignin-Composites.

Front. Chem. 6:124.

doi: 10.3389/fchem.2018.00124

\title{
One-Pot Enzymatic Production of Lignin-Composites
}

\begin{abstract}
Sabina Ion ${ }^{1}$, Cristina Opris ${ }^{1}$, Bogdan Cojocaru ${ }^{1}$, Madalina Tudorache ${ }^{1 *}$, Irina Zgura ${ }^{2}$, Aurelian C. Galca ${ }^{3}$, Adina M. Bodescu ${ }^{4}$, Madalin Enache ${ }^{5}$, Gabriel-Mihai Maria ${ }^{5}$ and Vasile I. Parvulescu ${ }^{1 *}$

${ }^{1}$ Department of Organic Chemistry, Biochemistry and Catalysis, Faculty of Chemistry, University of Bucharest, Bucharest, Romania, ${ }^{2}$ Laboratory of Optical Processes in Nanostructured Materials, National Institute of Materials Physics, Magurele, Romania, ${ }^{3}$ Laboratory of Multifunctional Materials and Structures, National Institute of Materials Physics, Magurele, Romania, ${ }^{4}$ Faculty of Food Engineering, Tourism and Environmental Protection, Research Center in Technical and Natural Sciences, "Aurel Vlaicu" University, Arad, Romania, ${ }^{5}$ Institute of Biology Bucharest of the Romanian Academy, Bucharest, Romania
\end{abstract}

A novel and efficient one-pot system for green production of artificial lignin bio-composites has been developed. Monolignols such as sinapyl (SA) and coniferyl (CA) alcohols were linked together with caffeic acid (CafAc) affording a polymeric network similar with natural lignin. The interaction of the dissolved SA/CA with CafAc already bound on a solid support $\left(\mathrm{S}_{\mathrm{C}_{2}} / \mathrm{S}_{\mathrm{C} 6}-\mathrm{Caf} A \mathrm{c}\right)$ allowed the attachment of the polymeric product direct on the support surface $\left(\mathrm{S}_{\mathrm{C} 2} / \mathrm{S}_{\mathrm{C} 6}-\mathrm{Caf} A \mathrm{Ac}-\mathrm{L}_{1}\right.$ and $\mathrm{S}_{\mathrm{C} 2} / \mathrm{S}_{\mathrm{C} 6}-\mathrm{Caf} A \mathrm{c}-\mathrm{L}_{2}$, from $C A$ and $S A$, respectively). Accordingly, this procedure offers the advantage of a simultaneous polymer production and deposition. Chemically, oxi-copolymerization of phenolic derivatives (SA/CA and CAfAc) was performed with $\mathrm{H}_{2} \mathrm{O}_{2}$ as oxidation reagent using peroxidase enzyme (2-1B mutant of versatile peroxidase from Pleurotus eryngii) as catalyst. The system performance reached a maximum of conversion for SA and CA of 71.1 and $49.8 \%$, respectively. The conversion is affected by the system polarity as resulted from the addition of a co-solvent (e.g., $\mathrm{MeOH}$, EtOH, or THF). The chemical structure, morphology, and properties of the bio-composites surface were investigated using different techniques, e.g., FIIR, TPD-NH$H_{3}$, TGA, contact angle, and SEM. Thus, it was demonstrated that the SA monolignol favored bio-composites with a dense polymeric surface, high acidity, and low hydrophobicity, while CA allowed the production of thinner polymeric layers with high hydrophobicity.

Keywords: bio-composites, oxi-copolymerization, monolignols, peroxidase enzyme, lignin

\section{INTRODUCTION}

Together with cellulose and hemicellulose, lignin is one of the most abundant natural polymers (Zakzeski et al., 2010). As an effect of the excessive valorization of the natural resources, the pulppaper and bio-refining industries are important providers of lignins (Lora and Glasser, 2002). However, the papermaking industry produces annually over 50 million tons of lignin wastes that are mainly used as an energy source (by direct combustion). Today, only $2 \mathrm{wt} \%$ of it is used for the polymeric industry (e.g., production of phenolic resins, polyurethane foams, bio-dispersants, or epoxy resins) (Gosselink et al., 2004b). Additionally, the wastes of the paper-pulp industry generate serious environmental pollution concerns. So that, an improvement of the market competitiveness of bio-refining industry is necessary. Accordingly, new perspectives for the valorization of the lignin are required. 
The general perception on the lignin is that of a "renewable chemical resource" formed from the assembling of functionalized aromatic entities with phenolic hydroxyl, alcoholic hydroxyl, carboxyl, or methoxy groups (Xiong et al., 2015; Aro and Fatehi, 2017). It presents an amorphous polymeric structure assumed to derive from up to three monolignols, e.g., coniferyl alcohol (CA), synapyl alcohol (SA), and coumaryl alcohol. These monolignols are incorporated in phenylpropanoid units expressed in varied modes such as guaiacyl, syringyl, and $p$ hydroxyphenyl connected by ether and carbon-carbon bonds in a complex three dimensional polymeric network (Nair et al., 2014). Thus, what is named lignin corresponds to a material with a large variety of chemical structures in which the above mentioned entities exist in various proportions. The differences are the direct consequence of its origin (type of the plant species, climate, geographical location) and the extraction process (Gosselink et al., 2004a).

As a bio-polymer, there are many potential value-added applications of lignin with significant impact on industry (Lee and Wendisch, 2017). Derivatization of lignin is often chosen as alternative leading to functionalized bio-polymers with role of the dispersant for cement, pesticide, coal-water slurry, rubberbased material, component of animal feed, surfactants, additive in oil drilling, stabilizers in colloidal suspensions, etc (Xiong et al., 2015; Aro and Fatehi, 2017). The lignin derivatives may also acquire antioxidant, antiviral, antibiotic, and/or anticarcinogenic activities (Yamamoto et al., 1997; Vinardell et al., 2008; Nair et al., 2014). Lignin has been used as alternative to phenol in phenolic resins and also in the composition of thermoplastic polyesters, polyurethanes, active carbons, and carbon fibers (Stewart, 2008; Thanh Binh et al., 2009; Nair et al., 2014). Additionally, ligninbased composites appeared as another low cost eco-friendly reinforcement attractive alternative (Morandim-Giannetti et al., 2012; Pupure et al., 2013; Qian et al., 2014; Thakur et al., 2014). They confirmed as important ingredients for composites with various properties like thermoplastic polymers (Pucciariello et al., 2004; Barzegari et al., 2013), thermosetting polymers (Yin et al., 2012; Stanzione et al., 2013), rubbers (Setua et al., 2000; Kramárová et al., 2007), or foam-based materials (Del SazOrozco et al., 2012; Luo et al., 2013). For this purpose, lignin and its derivatives were incorporated in bio-composites using both chemical or/and physical methods leading to homogeneous lignin particles (Nair et al., 2014) or colloidal spheres produced through self-assembly of acetylated lignin (Qian et al., 2014). However, such a valorization of lignin is still restricted due to two main reasons: its relative low reactivity and high heterogeneity of the polymeric mixture (Qu et al., 2015). Therefore, in the last years several chemical methods have been reported to enhance lignin reactivity, e.g., methylation, demethylation, acetylation, etc (Hu et al., 2011). Additionally, the lignin modification has been achieved via catalytic and solventfree methods (e.g., graft copolymerization of lactides to lignin catalyzed by triazabicyclodecenes) (Chung et al., 2013). However, the heterogeneity of the polymeric mixture of lignin is still a challenge today.

In this study, we investigated the production of lignincomposites (bio-composites) using monolignol fractions (e.g., SA or CA) with the aim to find another route for the valorization of lignin. There are evidences that lignin can be efficiently disrupted into a cocktail of monomers and oligomers (Lee et al., 2013; Opris et al., 2016, 2017). The produced fragments can be re-combined leading to an artificial lignin structure with enhanced homogeneity compared to the original lignin (Opris et al., 2018). In this study, particles functionalized with CafAc were used as solid supports allowing the synthesis of bio-composites. Therefore, monolignols can be directly oxipolymerized on the particles surface involving the CafAc as comonomer. Accordingly, the coverage process was called oxicopolymerization. The use of monolignols instead of whole lignin molecule ensures a better control of the composition of the polymeric layer providing to a good structural homogeneity of the polymeric material.

Usually, the functionalization of the particles surface (e.g. silica particles) by either physical or chemical methods requires a prior modification before covering with the polymeric layer. Most of the modifiers are derived from the fossil resources increasing the cost of these materials but also the toxicity (Zou et al., 2008). In this study, the particles surface (methacrylate) was functionalized with a natural modifier, i.e., CafAc (CafAc occurs frequently in fruits, grains, Salvia species) (Hao et al., 2015). Also, the polymeric layer (artificial lignin) covering the surface is bio-derived, mimicking the original lignin. In accordance to its characteristic structure and properties, the lignin-based polymer may afford the required modification of the particles for further bio-applications (e.g., carrier/support for enzymes). Additionally, the lignin bio-composites can provide an important example of a high value utilization of lignin residues.

The oxi-copolymerization of monolignols reported in this study for the synthesis of bio-composites was designed as a biocatalytic process where a peroxidase enzyme assisted the oxidation of both monolignols (SA or CA) and CafAc by means of $\mathrm{H}_{2} \mathrm{O}_{2}$. The developed system acts based on an onepot approach combining the oxi-copolymerization of SA/CA with CafAc, and the attachment of the resulted polymer on the support surface. From our best knowledge, it is the first time when a lignin-composite (bio-composite) with controlled and reproducible composition is prepared based on one-pot approach. Additionally, the influence of a co-solvent (e.g., $\mathrm{MeOH}, \mathrm{EtOH}, \mathrm{THF}$ ) on the oxi-copolymerization process has also been investigated. The production of the bio-composites was monitored using spectrophotometric as well as Folin-Ciocalteu analysis. Also, detailed characterization of the lignin-composites was performed using different techniques, e.g., FTIR, TPD- $\mathrm{NH}_{3}$, TGA, contact angle, and SEM.

\section{EXPERIMENTAL}

\section{Chemicals and Solutions}

The oxi-copolymerization process was performed with 2-1B mutant of versatile peroxidase original from Pleurotus eryngii, expressed in Saccharomyces cerevisae $\left(12.95 \mathrm{U} \mathrm{mL}^{-1}\right.$ enzyme activity) (Garcia-Ruiz et al., 2012; Molina-Espeja et al., 2014, 2015). 2-1B mutant was provided by Dr. Miguel Alcalde (Institute of Catalysis, CSIC, Madrid, Spain). The solid support 
of bio-composites ( $\mathrm{S}_{\mathrm{C} 2}$-amino $\mathrm{C} 2$ methacrylate, ECR8309F and $\mathrm{S}_{\mathrm{C} 6}$-amino C6 methacrylate, ECR8409F) was kindly offered by the Purolite Life Sciences Company. Both supports were constituted from the beads (150-300 $\mu \mathrm{m}$ of diameter) originally functionalized with $-\mathrm{NH}_{2}$ groups using methacrylate crosslinkers.

Ten milli molars of PBS (phosphate buffer saline) solution ( $\mathrm{pH}=7.4$ ) was used as aqueous buffer solution. Its composition consisted of: $8 \mathrm{~g} \mathrm{NaCl}, 0.2 \mathrm{~g} \mathrm{KCl}, 1.43 \mathrm{~g} \mathrm{Na} 2 \mathrm{HPO}_{4} \times 2 \mathrm{H}_{2} \mathrm{O}$ and $0.34 \mathrm{~g} \mathrm{KH}_{2} \mathrm{PO}_{4}$ in $1 \mathrm{~L}$ distilled water. $10 \mathrm{mM}$ MES $(2-(\mathrm{N}-$ morpholino)ethanesulfonic acid) buffer $(\mathrm{pH}=4.7)$ was prepared by dissolving a corresponding MES mass in distilled water followed of $\mathrm{NaOH}$ addition for adjusting the $\mathrm{pH}$ value of the solution.

CA, SA, CafAc, 1-ethyl-3-(3-dimethylaminopropyl) carbodiimide (ECD), $30 \mathrm{wt} \%$ solution of hydrogen peroxide $\left(\mathrm{H}_{2} \mathrm{O}_{2}\right)$, methanol $(\mathrm{MeOH})$, ethanol $(\mathrm{EtOH})$, and tetrahydrofuran (THF) were of analytic purity and purchased from Sigma-Aldrich. Stock solutions of monolignols (e.g., CA and SA) with concentration of $10 \mathrm{mg} \mathrm{mL}^{-1}$ were prepared in $\mathrm{MeOH}$.

\section{$\mathrm{S}_{\mathrm{C}_{2}} / \mathrm{S}_{\mathrm{C} 6}$ Functionalization}

For the attachment of the lignin polymer, the solid supports $\mathrm{S}_{\mathrm{C} 2}$ and $\mathrm{S}_{\mathrm{C} 6}$ were functionalized with CafAc in order to ensure the phenolic structures on the particles surface. $0.2 \mathrm{~g}$ of $\mathrm{S}_{\mathrm{C} 2} / \mathrm{S}_{\mathrm{C} 6}$ support were dispersed in $10 \mathrm{~mL}$ solution containing $10 \mathrm{mg} \mathrm{mL}^{-1}$ CafAc in MES (10 mM, pH = 4.7). $0.96 \mathrm{~g}$ of EDC was added in the suspension under continuous shaking for activating the $-\mathrm{COOH}$ groups of CafAc in order to interact with $-\mathrm{NH}_{2}$ groups on the support. Coupling of CafAc on support surface was performed over the night, at room temperature under gentle agitation. Then, the functionalized particles $\left(\mathrm{S}_{\mathrm{C} 2}-\mathrm{CafAc}\right.$ and $\mathrm{S}_{\mathrm{C} 6}$-CafAc) were separated by centrifugation and washed several times with MES buffer and distilled water.

\section{Bio-Composites Preparation}

The bio-composites construction was performed in one-pot system by enzyme oxi-copolymerization of monolignols (e.g., $\mathrm{CA}$ or SA) directly on the surface of the previously prepared supports $\left(\mathrm{S}_{\mathrm{C} 2} / \mathrm{S}_{\mathrm{C} 6}\right.$ functionalized with CafAc, section $\mathrm{S}_{\mathrm{C} 2} / \mathrm{S}_{\mathrm{C} 6}$ functionalization). One hundred microliters of monolignol stock solution $\left(10 \mathrm{mg} \mathrm{mL}^{-1} \mathrm{SA} / \mathrm{CA}\right.$ in $\left.\mathrm{MeOH}\right)$ were diluted with 300 $\mu \mathrm{L}$ PBS (10 mM, pH 7.4). $10 \mathrm{mg}$ of functionalized support $\left(\mathrm{S}_{\mathrm{C} 2}\right.$ CafAc or $\mathrm{S}_{\mathrm{C} 6}$-CafAc) were added in the solution followed by the addition of $10 \mu \mathrm{L} \mathrm{H}_{2} \mathrm{O}_{2}(30 \%)$ and $50 \mu \mathrm{L} \mathrm{2-1B}$ peroxidase mutant $\left(\mathrm{H}_{2} \mathrm{O}_{2}\right.$ :enzyme molar ratio of $\left.1760: 1\right)$. The reaction mixture was incubated at $40^{\circ} \mathrm{C}$ in a thermo-shaker $(100 \mathrm{rpm})$ over night. For comparison, the monolignols polymerization was also performed in the absence of the functionalized support (homogeneous system).

The separation of the bio-composite was performed using a set up protocol detailed in Scheme 1. The reacted mixture was treated with $300 \mu \mathrm{L} \mathrm{MeOH}$ for biocatalyst precipitation and solubilization of unattached oligomers. The centrifugation of the new mixture allowed the separation of the two phases: the liquid phase (supernatant) with unreacted monolignols and/or

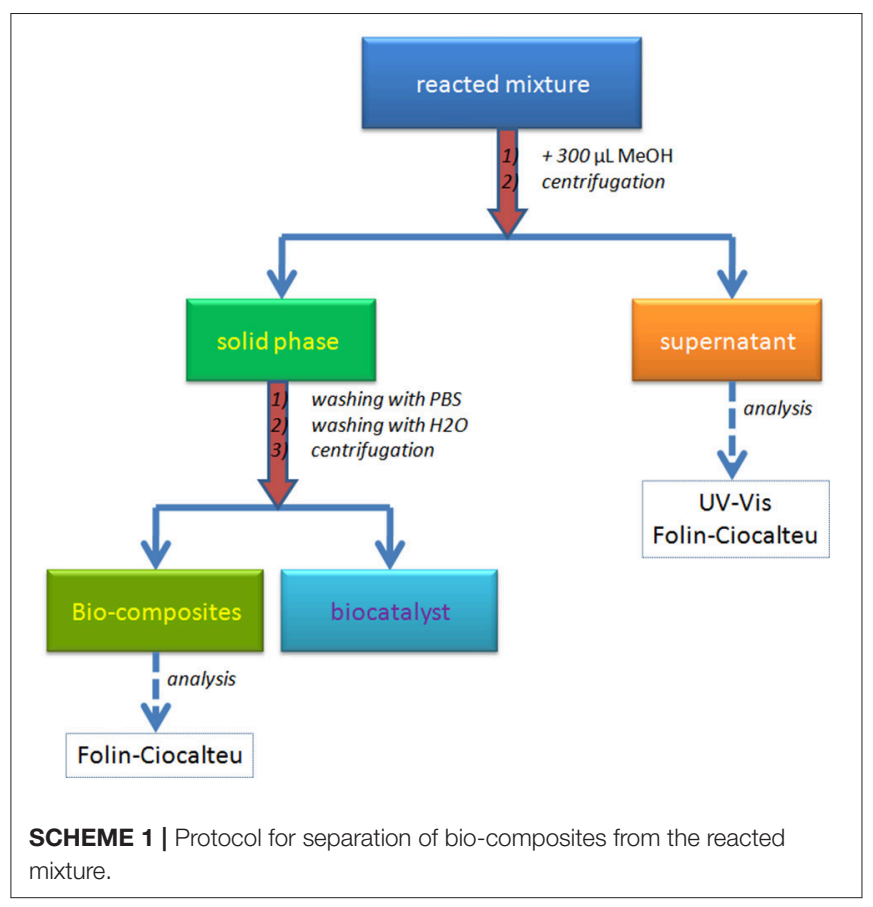

oligolignols, and the solid phase containing the bio-composites and precipitated biocatalyst. The supernatant was analyzed using UV-Vis and Folin-Ciocalteu methods. While the UV-Vis analysis allowed the determination of the aromatic content, the FolinCiocalteu method permeated the detection of the phenolic - $\mathrm{OH}$ groups. The solid phase was washed consecutively with PBS and distilled water in order to remove the precipitated enzyme (biocatalyst) from the bio-composites surface. The centrifugation step allowed the separation of the bio-composites and the recovery of the enzyme as a PBS solution. Bio-composite surface was investigated based on Folin-Ciocalteu approach.

\section{Analysis of Reacted Mixture}

UV-Vis method was used for the determination of mono-/oligolignols (phenolic derivatives) in the liquid phase (Scheme 1). The sample absorbance was read at $280 \mathrm{~nm}$ with a Specord 250 (Analytik Jena). The conversion of monolignols based on the oxi-copolymerization process was calculated using the absorbance of the solutions before and after the reaction. FolinCiocalteu analysis was performed for the determination of free -OH groups on the aromatic ring (Singleton et al., 1999). The protocol was adapted for the investigation of the bio-composites and the liquid phase (Scheme 1). Twenty microliters of sample solution (supernatant or $10 \mathrm{mg} / \mathrm{mL}$ bio-composites in $\mathrm{MeOH}$ ) were dispersed in $1.5 \mathrm{~mL}$ of distilled water and the resulted mixture was enreached with $100 \mu \mathrm{L}$ Folin-Ciocalteu reagent and $300 \mu \mathrm{L}$ saturated solution of sodium carbonate as supporting medium (adjusting the $\mathrm{pH}$ of solution to a basic value). After $2 \mathrm{~h}$ incubation time, the mixture was centrifuged and the supernatant absorbance was read at $765 \mathrm{~nm}$.

GPC analysis was performed for the determination of the average molecular weight of the polymers produced in the 
absence of the functionalized support. The analysis approach was detailed in our previous report (Opris et al., 2018). Thus, the GPC analysis was carried out using an Agilent Technologies instrument (Model 1260) equipped with two columns (Zorbax PSM 60-S, $6.5 \times 250 \mathrm{~mm}, 5 \mu \mathrm{m}$, and Polargel-M, $300 \times 7.5 \mathrm{~mm}$ ) and a multidetection unit (Refractive Index, Light Scattering, and Viscosity detectors). Experimental conditions were set up at $1 \mathrm{~mL} \mathrm{m^{-1 }}$ THF as mobile phase, $100 \mu \mathrm{L}$ injection volume of sample, and temperature of the detectors and columns of $35^{\circ} \mathrm{C}$. The calibration of the GPC system was performed using polystyrene standards in the range of $162-10,000 \mathrm{~g} \mathrm{~mol}^{-1}$. The Agilent GPC/SEC Software (Version 1.1, Agilent Technologies) was utilized for the determination of the average molecular weight (MW).

\section{The Characterization of the Bio-Composites}

FTIR spectra of bio-composites and simple/functionalized supports were recorded using Vertex 70 (Bruker, Ettlingen, Germany) spectrophotometer equipped with the Total Attenuated Reflectance cell in the range of $600-2000 \mathrm{~cm}^{-1}$. Sixteen scans were collected with a resolution of $4 \mathrm{~cm}^{-1}$ in the range of $600-4000 \mathrm{~cm}^{-1}$.

The total acidity was evaluated by temperature-programmed desorption of ammonia (TPD- $\mathrm{NH}_{3}$ ) using a Micromeritics Chemisorb 2750 instrument. Before $\mathrm{NH}_{3}$ desorption, the samples were heated to $80^{\circ} \mathrm{C}\left(20^{\circ} \mathrm{C} \mathrm{min}{ }^{-1}\right)$ in $30 \mathrm{~mL}$ high pure Helium flow. Subsequently, the samples were cooled down to room temperature in helium flow. $\mathrm{NH}_{3}$ adsorption was performed under ambient conditions and saturation for about $60 \mathrm{~min}$ in a flow of $10 \%$ ammonia in Helium $\left(30 \mathrm{~mL} \mathrm{~min}^{-1}\right)$. Then, the samples were purged in a Helium flow until a constant baseline level was attained. The desorption of $\mathrm{NH}_{3}$ was carried out with the linear heating rate $\left(10^{\circ} \mathrm{C} \mathrm{min}^{-1}\right)$ in a flow of Helium until $300^{\circ} \mathrm{C}$.

The termo-gravimetric analysis (TGA) was performed with a Shimadzu instrument (SDT Q600) in order to determine the thermo stability of the bio-composite according to the original/functionalized support. Maximum $10 \mathrm{mg}$ of sample were used. The analysis was carried out at increasing temperature with a rate of $10^{\circ} \mathrm{C} \mathrm{min}^{-1}$ in the range of $30-600^{\circ} \mathrm{C}$ under $\mathrm{N}_{2}$ atmosphere.

Static contact angle of bio-composites was measured with a Drop Shape Analysis System, model DSA100 (Kruss GmbH). The sample was placed on a horizontal stage, under the tip of a waterdispensing disposable blunt-end stainless steel needle with an outer diameter of $0.5 \mathrm{~mm}$. The water droplet $(1 \mu \mathrm{L})$ was delivered on the sample surface by the needle attached to a syringe pump controlled with a PC (through DSA ${ }^{\circledR}$ software supplied with the instrument). The viewing camera for taking the picture was positioned to observe the droplet under an angle of about $2-3^{\circ}$ with respect to the plane of the sample surface supporting the droplet. The tests were carried out at room temperature. The contact angle was measured by fitting a polynomial equation of second degree or a circle equation to the shape of the sessile drop. Then, the slope of the tangent to the drop at the liquid-solid vapor interface line was calculated. (Zgura et al., 2010, 2013; Popescu et al., 2011; Duta et al., 2012; Preda et al., 2013).

For scanning electron microscopy (SEM) analysis, freeze, and dried particles (e.g., bio-composites and original/functionalized supports) were examined using a Jeol instrument (JSM-6610LV). The pretreatment of the samples followed the dispersion of the particles in EtOH solution (30\%) and deposition of $10 \mu \mathrm{L}$ suspension on the microscopic blade covered with gold layer. After EtOH evaporation at room temperature, prepared blades were dried in vacuum followed by metal coating using a sputter coater (Jeol auto fine coater, JFC-1300). SEM investigations were performed under high vacuum conditions.

\section{RESULTS AND DISCUSSION \\ Co-polymerization of Monolignols for the Construction of Bio-Composites}

The concept of the one-pot synthesis of bio-composites has been described above. The oxi-copolymerization of monolignols (e.g., $\mathrm{CA}$ or $\mathrm{SA})$ was directly performed on the supports $\left(\mathrm{S}_{\mathrm{C} 2}\right.$ and $\left.\mathrm{S}_{\mathrm{C} 6}\right)$ surface functionalized with CafAc $\left(\mathrm{S}_{\mathrm{C} 2}\right.$-CafAc and $\mathrm{S}_{\mathrm{C} 6}$-CafAc $)$ in the presence of the $2-1 \mathrm{~B}$ mutant of versatile peroxidase as catalyst using an adapted procedure (Opris et al., 2018). In this study CafAc used as a co-monomer afforded the oxi-copolymerization of monolignols. CA allowed the production of $\mathrm{S}_{\mathrm{C} 2} / \mathrm{S}_{\mathrm{C} 6}$-CafAc$\mathrm{L}_{1}$ bio-composite, while the oxi-copolymerization of SA led to $\mathrm{S}_{\mathrm{C} 2} / \mathrm{S}_{\mathrm{C} 6}-\mathrm{CafAc}-\mathrm{L}_{2}$.

Under the investigated homogeneous conditions, the oxicopolymerization of monolignols (SA/CA) and CafAc led to the results presented in Table 1. A higher conversion was achieved for SA compared to CA (65.3 vs. 21.1\%) leading to polymers with different molecular weights (3500 and $856 \mathrm{Da}$ for SA and CA, respectively). The affinity of the biocatalyst for the monolignols can be a reasonable explanation of the system behavior. These results are in accordance with the previous report (Opris et al., 2018).

Under heterogeneous conditions, i.e., with SA/CA dissolved in liquid phase, and CafAc attached on the particles $\left(\mathrm{S}_{\mathrm{C} 2} / \mathrm{S}_{\mathrm{C} 6}{ }^{-}\right.$ CafAc), the monolignols and immobilized CafAc were linked together in a polymeric structure miming the natural lignin directly attached on the particles surface (Table 1). This heterogeneous design allowed to improve the conversion of

TABLE 1 | Efficiency of the oxi-copolymerization process.

\begin{tabular}{lcccccc}
\hline Solid support & \multicolumn{2}{c}{ SA } & & \multicolumn{2}{c}{ CA } \\
\cline { 2 - 3 } \cline { 5 - 6 } & $\mathbf{C}(\%)$ & MW (Da) & & $\mathbf{C}(\%)$ & MW (Da) \\
\hline- & 65.3 & 3500 & & 21.1 & 856 \\
$\mathrm{~S}_{\mathrm{C} 2}$-CafAC & 71.1 & - & & 49.8 & - \\
$\mathrm{S}_{\mathrm{C} 6}$-CafAC & 65.7 & - & & 36.3 & - \\
\hline
\end{tabular}

Experimental conditions: $2 \mathrm{mg} / \mathrm{mL}$ monolignol (SA CA), $1.295 \mathrm{U} \mathrm{mL}^{-1} 2-1 B$ peroxidase mutant, $0.6 \% \mathrm{H}_{2} \mathrm{O}_{2}$, and $20 \mathrm{mg} / \mathrm{mL}$ functionalized support for heterogeneous copolymerization in PBS (10 mM, pH = 7.4); $40^{\circ} \mathrm{C}, 24 \mathrm{~h}$ and $100 \mathrm{rpm}$. C, conversion of the oxi-copolymerization process. MW, average molecular weight of copolymer. 
monolignols compared to homogeneous system keeping the same advantage of SA vs. CA. Different conversions were also determined as a function of the functionalized support $\left(\mathrm{S}_{\mathrm{C} 2}\right.$ CafAc and $\mathrm{S}_{\mathrm{C} 6}$-CafAc) demonstrating that the solid support influenced the co-polymerization process (Table 1).

Important parameters of this process are the loading of the polymeric products on the solid surface and the percent of the oligomers in the residual phase (supernatant, see Scheme 1). To determine these, both the supernatants and bio-composites were analyzed using spectrophotometric (UV-Vis) and FolinCiocalteu approaches (F-C) (Scheme 1). Moreover, the results were converted in the concentration of recovered monolignols (i.e., the ratio between the concentration of monolignol in/on residues/bio-composite and initial concentration of monolignol) (Table 2). The relative low difference between the F-C and UVVis results can be an indicative for the insignificant content of the oligolignols in the supernatant. Moreover, the UVVis results should be interpreted with caution because of the production of quinone derivatives as secondary products of co-oxipolymerization process. For bio-composites, the same measurements evidenced the presence of small concentration of free $\mathrm{OH}$ groups (around 10 times lower than in the supernatant). The participation of the $\mathrm{OH}$ groups into the formation of the etheric bonds of the synthetic lignin is a plausible explanation.

TABLE 2 | Evaluation of supernatant content in monolignols and oligolignols using spectrophotometric (UV-Vis) and Folin-Ciocalteu $(F-C)$ methods (recovered concentration, \%).

\begin{tabular}{llccccc}
\hline Solid support & & \multicolumn{2}{c}{ SA } & & \multicolumn{2}{c}{ CA } \\
\cline { 3 - 4 } \cline { 6 - 7 } & & UV-Vis & F-C & & UV-Vis & F-C \\
\hline $\mathrm{S}_{\mathrm{C} 2}$-CafAC & Supernatant & 28.90 & 24.70 & & 58.37 & 52.64 \\
& Bio-composite & - & 2.78 & & - & 5.51 \\
$\mathrm{~S}_{\mathrm{C} 6}$-CafAC & Supernatant & 34.30 & 24.41 & & 74.07 & 65.41 \\
& Bio-composite & - & 2.89 & & - & 3.70
\end{tabular}

The effect of the co-solvent (e.g., $\mathrm{MeOH}, \mathrm{EtOH}, \mathrm{THF}$ ) has also been evaluated showing a different influence depending on the monolignol type (Figure 1). For SA, the use of $\mathrm{MeOH}$ as cosolvent led to better results affording a higher conversion for $\mathrm{S}_{\mathrm{C}^{-}}{ }^{-}$ CafAc support compared to $\mathrm{S}_{\mathrm{C} 2}$-CafAc. For CA, the presence of the co-solvent doubled the conversion of monolignols. However, the reproducibility was low, and high standard deviation has been determined for co-solvent (e.g., $\mathrm{MeOH}, \mathrm{EtOH}, \mathrm{THF}$ ). In conclusion, poor reproducibility for the bio-composite production using a co-solvent enforces the use of $\mathrm{H}_{2} \mathrm{O}$ despite of smaller conversions.

\section{Characterization of the Bio-Composite}

FTIR analysis confirmed the attachment of the artificial lignin on the support surface during the oxi-copolymerization (Figures $\mathrm{S} 1-\mathrm{S} 3$ ). Table 3 presents the differences between the spectra collected for $\mathrm{S}_{\mathrm{C} 2}$-CafAc- $\mathrm{L}_{1} / \mathrm{L}_{2}$ and $\mathrm{S}_{\mathrm{C} 6}-\mathrm{CafAc}-\mathrm{L}_{1} / \mathrm{L}_{2}$, and those of the original/functionalized supports $\left(\mathrm{S}_{\mathrm{C} 2}, \mathrm{~S}_{\mathrm{C} 6}, \mathrm{~S}_{\mathrm{C} 2}\right.$-CafAc and $\mathrm{S}_{\mathrm{C} 6}$-CafAc). The attachment of the CafAc on the solid support led to a consistent modification of the spectrum (Figure S1). The intensity of the $\mathrm{OH}$ band stretching at $3370 \mathrm{~cm}^{-1}$ on the particles surface $\left(\mathrm{S}_{\mathrm{C} 2} / \mathrm{S}_{\mathrm{C} 6}\right)$ (Poletto and Zattera, 2013) decreased for $\mathrm{S}_{\mathrm{C} 2} / \mathrm{S}_{\mathrm{C} 6}$-CafAc. Additionally, new bands occurred at 1041 $\mathrm{cm}^{-1}$ and $1563-1564 \mathrm{~cm}^{-1}$ due to the presence of $\mathrm{C}-\mathrm{O}$ bonds on the aromatic ring and the formation of amide bonds (CO$\mathrm{NH}$ ) by the attachment of CafAc on the support surface. Both functionalized supports $\left(\mathrm{S}_{\mathrm{C} 2}\right.$-CafAc and $\mathrm{S}_{\mathrm{C} 6}$-CafAc) have similar FTIR spectra (Figure $\mathrm{S} 1$ ).

$\mathrm{S}_{\mathrm{C} 2}-\mathrm{CafAc}-\mathrm{L}_{1} / \mathrm{L}_{2}$ and $\mathrm{S}_{\mathrm{C} 6}-\mathrm{CafAc}-\mathrm{L}_{1} / \mathrm{L}_{2}$ presented modified spectra in the regions of $3700-3000 \mathrm{~cm}^{-1}$ and $1200-700 \mathrm{~cm}^{-1}$ compared with $\mathrm{S}_{\mathrm{C} 2}$-CafAc and $\mathrm{S}_{\mathrm{C} 6}$-CafAc, respectively (Figure S2). The differences are summarized in Table 3. The shoulder at around $3600 \mathrm{~cm}^{-1}$ is attributed to an aliphatic $\mathrm{OH}$ group of the monolignol structure (Poletto and Zattera, 2013), while the new bands at $2952 / 2953$ and $2942 / 2943 \mathrm{~cm}^{-1}$ were to the $\mathrm{C}-\mathrm{H}$ stretching vibration of the methyl and methylene groups introduced by the SA and CA monolignols (Xiong et al., 2015). The presence of the aromatic ring has been confirmed
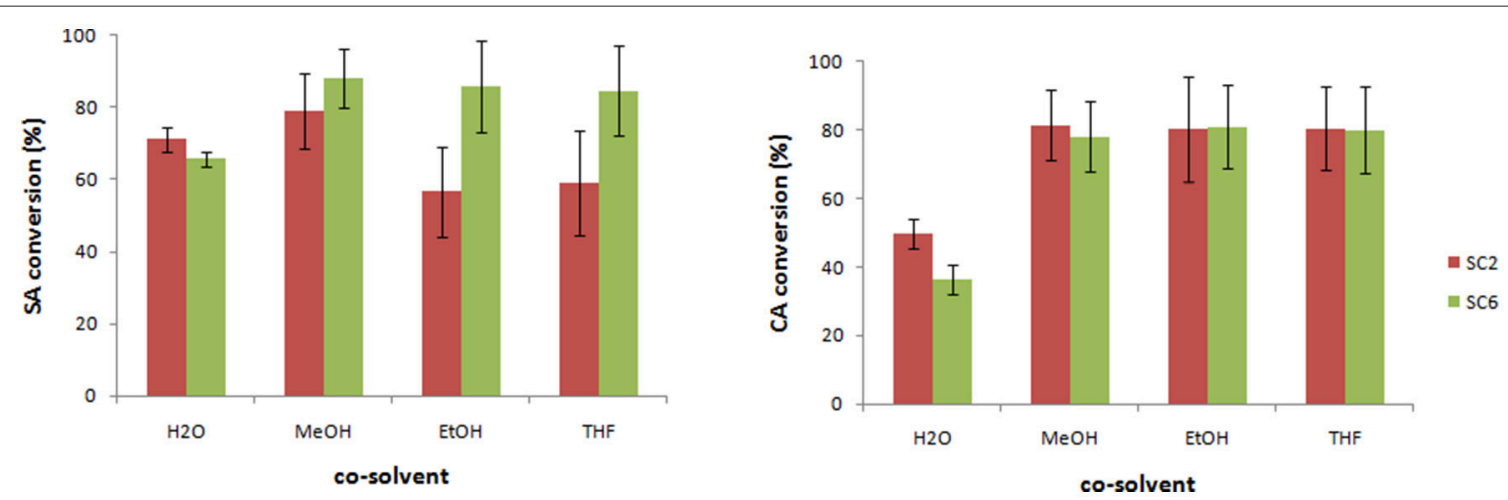

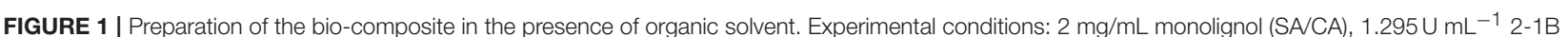
peroxidase mutant, $0.6 \% \mathrm{H}_{2} \mathrm{O}_{2} 20 \mathrm{mg} / \mathrm{mL}$ functionalized support for heterogeneous co-polymerization, and 6\% added solvent ( $\mathrm{H}_{2} \mathrm{O}$, MeOH, EtOH, THF) in $\mathrm{PBS}$ (10 mM, pH $=7.4) ; 40^{\circ} \mathrm{C}, 24 \mathrm{~h}$ and $100 \mathrm{rpm}$. (Triplicates analysis were performed). 
TABLE 3 | Summary of the specific bands observed for bio-composites, original, and functionalized supports.

\begin{tabular}{|c|c|c|c|c|c|c|c|}
\hline \multirow[t]{2}{*}{ Assignment } & \multicolumn{7}{|c|}{ Band position $\left(\mathrm{cm}^{-1}\right)$} \\
\hline & $\mathrm{S}_{\mathrm{C} 2 / \mathrm{C} 6}$ & $\mathrm{~S}_{\mathrm{C} 2}$-CafAc & $\mathrm{S}_{\mathrm{C} 6}-$ CafAc & $\mathrm{S}_{\mathrm{C} 2}-$ CafAC-L1 & $S_{C 6}-$ CafAc- $L_{1}$ & $\mathrm{~S}_{\mathrm{C} 2}-$ CafAc- $\mathrm{L}_{2}$ & $S_{C 6}-$ CafAc- $L_{2}$ \\
\hline $\mathrm{O}-\mathrm{H}$ stretching & 3370 & 3361 & 3368 & 3385 & 3378 & 3392 & 3364 \\
\hline \multirow[t]{2}{*}{ Aromatic methyl and methylene groups } & - & - & - & 2953 & 2942 & 2952 & 2943 \\
\hline & - & 2724 & 2721 & - & - & - & - \\
\hline$-\mathrm{CO}-\mathrm{NH}-$ & - & 1563 & 1564 & - & - & - & - \\
\hline $\mathrm{C}-\mathrm{C}$ in aromatic skeleton & - & - & - & 1544 & 1538 & 1546 & 1540 \\
\hline Syringyl units & - & - & - & - & - & 1120 & 1120 \\
\hline C-O deformation of aromatic ethers & - & - & - & 1080 & 1080 & 1076 & 1076 \\
\hline $\mathrm{C}-\mathrm{O}$ on the aromatic skeleton & - & 1041 & 1041 & - & - & - & - \\
\hline $\mathrm{C}-\mathrm{H}$ out of plane for guaiacyl units & - & - & - & 859 & 859 & 858 & 859 \\
\hline
\end{tabular}

by the bands in the range $1538-1546 \mathrm{~cm}^{-1}$. The new band at $1120 \mathrm{~cm}^{-1}$ observed for $\mathrm{S}_{\mathrm{C} 2} / \mathrm{S}_{\mathrm{C} 6}-\mathrm{CafAc}-\mathrm{L}_{2}$ represents an evidence of the presence of the syringyl units detected in the polymeric layer of the bio-composites. Guaiacyl units were also detected at low intensity at 858 and $859 \mathrm{~cm}^{-1}$ (Poletto and Zattera, 2013). However, the band at $1264 \mathrm{~cm}^{-1}$ typical for guaiacyl (Poletto and Zattera, 2013; Fitigău et al., 2015) is not visible for $\mathrm{S}_{\mathrm{C} 2} / \mathrm{S}_{\mathrm{C} 6}-\mathrm{CafAc}-\mathrm{L}_{1}$ due to a superposition with an already existing band at $1257 \mathrm{~cm}^{-1}$. Poor covering of the support with polymers from CA (Table 1) can represent another reason for the absence of this band. All bio-composites showed also absorbance bands at 1076 and $1080 \mathrm{~cm}^{-1}$ attributed to etheric groups $(\mathrm{C}-\mathrm{O}-\mathrm{C})$ connecting the aromatic rings $(\mathrm{Qu}$ et al., 2015; Xiong et al., 2015). This is also an evidence for the production of the artificial lignin onto the bio-composite surface.

FTIR spectra of bio-composites prepared in the presence of co-solvent showed differences between $\mathrm{MeOH}$ and $\mathrm{EtOH}$, on one side, and THF, on the other side (Figure S3). Thus, the presence of $\mathrm{MeOH}$ or EtOH led to structures for which the bands at 1076 and $1078 \mathrm{~cm}^{-1}$ were not present anymore while those at 973/949 and $858 \mathrm{~cm}^{-1}$ presented a dramatic decrease in the intensity. These results confirm that $\mathrm{MeOH}$ and $\mathrm{EtOH}$ inhibit the formation of the artificial lignin structures, and especially of the guaiacyl units. So, the increased conversion for the oxi-copolymerization in the presence of an organic solvent does not correspond to the formation of lignolic structures (i.e., guaiacyl units).

The acidity of the bio-composites has been evaluated from TPD-NH $\mathrm{N}_{3}$ measurements (Table 4). The bio-composites incorporating CA have similar acidic properties with the functionalized support confirming the conservation of the phenolic $\mathrm{OH}$ group $\left(\mathrm{NH}_{3}\right.$ desorption peaks at $\left.197^{\circ} \mathrm{C}\right)$. However, the number of acidic centers has been doubled for the biocomposite showing an enrichment of phenolic $\mathrm{OH}$ owing of the synthetic lignin structure. CA and SA led to bio-composites with two different acidity centers $\left(\mathrm{NH}_{3}\right.$ desorption peaks at 197 and $210^{\circ} \mathrm{C}$ ) that were assigned to phenolic and aliphatic $\mathrm{OH}$ groups. Also, the total number of the acid centers was higher for SA polymer than for the corresponding CA-based bio-composite. These results fit the values of the conversion calculated for the oxi-copolymerization of the monolignols (Table 1).
TABLE 4 | Acidity of bio-composites compared to the CafAc-functionalized support based on TPD- $\mathrm{NH}_{3}$.

\begin{tabular}{lcc}
\hline Bio-composite & \multicolumn{2}{c}{ Acidity $(\mu \mathrm{mol} / \mathrm{g})$} \\
\cline { 2 - 3 } & Phenolic $\mathbf{~ O H}$ & Aliphatic $\mathbf{~ O H}$ \\
\hline $\mathrm{S}_{\mathrm{C} 6}-\mathrm{CafAC}$ & 26 & - \\
$\mathrm{S}_{\mathrm{C} 6}-\mathrm{CafAC}-\mathrm{L}_{1}$ & 52 & - \\
$\mathrm{S}_{\mathrm{C} 6}-$ CafAc- $\mathrm{L}_{2}$ & 37 & 44 \\
\hline
\end{tabular}

The thermo-stability of produced lignin bio-composites $\left(\mathrm{S}_{\mathrm{C} 2}-\mathrm{CafAc}-\mathrm{L}_{1} / \mathrm{L}_{2}\right.$ and $\mathrm{S}_{\mathrm{C} 6}-$ CafAc- $\left.\mathrm{L}_{1} / \mathrm{L}_{2}\right)$ compared to the original/functionalized supports $\left(\mathrm{S}_{\mathrm{C} 2}, \mathrm{~S}_{\mathrm{C} 6}, \mathrm{~S}_{\mathrm{C} 2}\right.$-CafAc, $\mathrm{S}_{\mathrm{C} 6}$-CafAc) has been evaluated in the temperature range of $30-600^{\circ} \mathrm{C}$ (Figure 2). TGA profiles of bio-composites were quit similar. The mass loss up to $230^{\circ} \mathrm{C}$ is mainly due to the removal of water $(<8 \mathrm{wt} \%)$. The differences in the shape of the profiles for the functionalized support and corresponding bio-composite may account the degradation of propanoid chain of the polymer (Strzemiecka et al., 2016). Further heating (230$430^{\circ} \mathrm{C}$ ) corresponded to a larger mass loss (about $45 \%$ ). This is related to the decomposition of polymeric material linked to the support surface $\left(\mathrm{L}_{1} / \mathrm{L}_{2}\right)$. The heterogeneity of the bio-composite surface (artificial lignin) is confirmed by the different losses in this temperature range. However, an important information provided by these results is the increased thermo-stability as effect of the covering the support with synthetic lignin. This is confirmed by the shift of the thermal effects to higher temperatures in accordance to literature data (Brebu et al., 2013; Brostow et al., 2016; Strzemiecka et al., 2016).

The investigation of surface hydrophobicity was performed using contact angle measurements of distilled water onto CafAcfunctionalized silica chips (S-CafAc) and corresponding biocomposites (S-CafAc- $\mathrm{L}_{1} / \mathrm{L}_{2}$ ) (Figure 3). The contact angle of the chip (S) was of $29^{\circ}$, while for the bio-composites increased to $63^{\circ}$ for CA-based polymer or decreased to $18^{\circ}$ for the SA-based polymer. These results indicate an enhancement of the hydrophobicity for the chip surface covered by CA monolignol reported also in the previous literature for natural lignin (Xiong et al., 2015; Salanti et al., 2016). Moreover, the artificial lignin 
prepared by oxi-copolymerization is more hydrophobic than some natural lignins (e.g., soda lignin from Triticum sp and Saccharumofficiarum with a $35^{\circ}$ contact angle) (Buono et al., 2016). SA led to a hydrophilic polymer than the support as an effect of the ratio between phenolic and alkyl $\mathrm{OH}$ groups. For $\mathrm{L}_{1}$, the hydrophobicity of the aromatic ring was enforced due to the relative low density of $\mathrm{OH}$ confirmed by the TPD- $\mathrm{NH}_{3}$ measurements (Table 4). The hydrophilicity of the $\mathrm{L}_{2}$ surface is also according to $\mathrm{TPD}-\mathrm{NH}_{3}$ results (Table 4). The hydrophobicity/hydrophilicity property of biocomposites represents an important characteristics for their further application as support/carrier of biomolecules (e.g., immobilization of lipase enzyme on hydrophobic surface turn on the enzyme in active form; Thomas et al., 2005).

SEM images of bio-composites and original/functionalized supports are presented in Figure 4. The parent particles $\left(\mathrm{S}_{\mathrm{C} 2}\right.$ and $\mathrm{S}_{\mathrm{C} 6}$ ) presented a smooth surface, while the functionalized particles $\left(\mathrm{S}_{\mathrm{C} 2} / \mathrm{S}_{\mathrm{C} 6}-\mathrm{CafAc}\right)$ showed roughened morphology. Differences in the morphologies of the bio-composites $\left(\mathrm{S}_{\mathrm{C} 2} / \mathrm{S}_{\mathrm{C} 6}\right.$-CafAc- $\left.\mathrm{L}_{1} / \mathrm{L}_{2}\right)$ were also induced by the monolignol oxi-copolymerization (the polymeric layer looks more dense for $\mathrm{L}_{2}$ than $\left.\mathrm{L}_{1}\right)$.
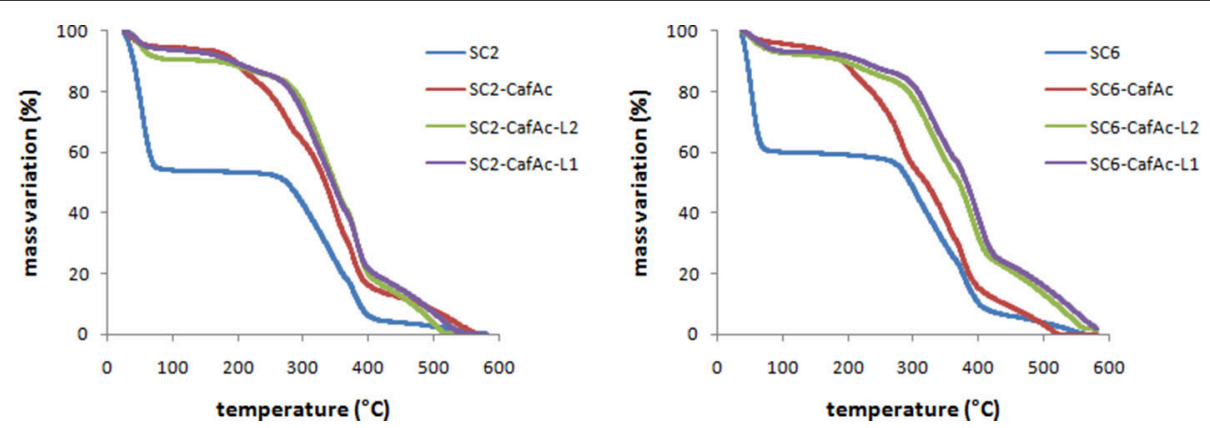

FIGURE 2 | TGA diagrams of the bio-composites $\left(\mathrm{S}_{\mathrm{C} 2}\right.$-CafAc- $\mathrm{L}_{1} / \mathrm{L}_{2}$ and $\left.\mathrm{S}_{\mathrm{C} 6}-\mathrm{CafAc}_{\mathrm{C}} \mathrm{L}_{1} / \mathrm{L}_{2}\right)$ related to original/functionalized support $\left(\mathrm{S}_{\mathrm{C} 2}, \mathrm{~S}_{\mathrm{C} 6}, \mathrm{~S}_{\mathrm{C} 2}-\mathrm{CafAc}_{\mathrm{C}}\right.$ $\mathrm{S}_{\mathrm{C} 6}$-CafAc).

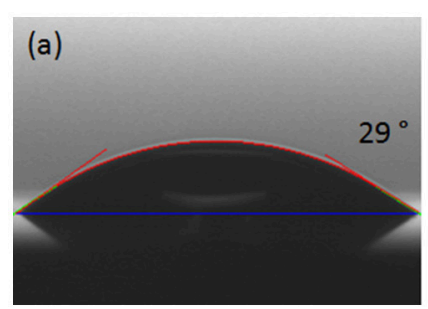

(b)

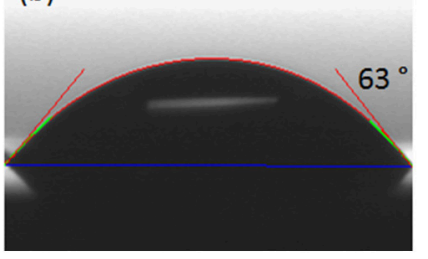

(c)

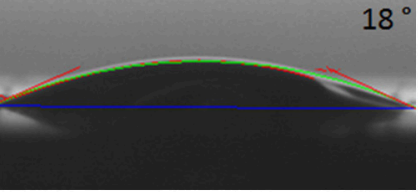

FIGURE 3 | Measurements of static contact angle of (a) S-CafAc, (b) S-CafAc- $L_{1}$, and (c) S-CafAc- $L_{2}$.
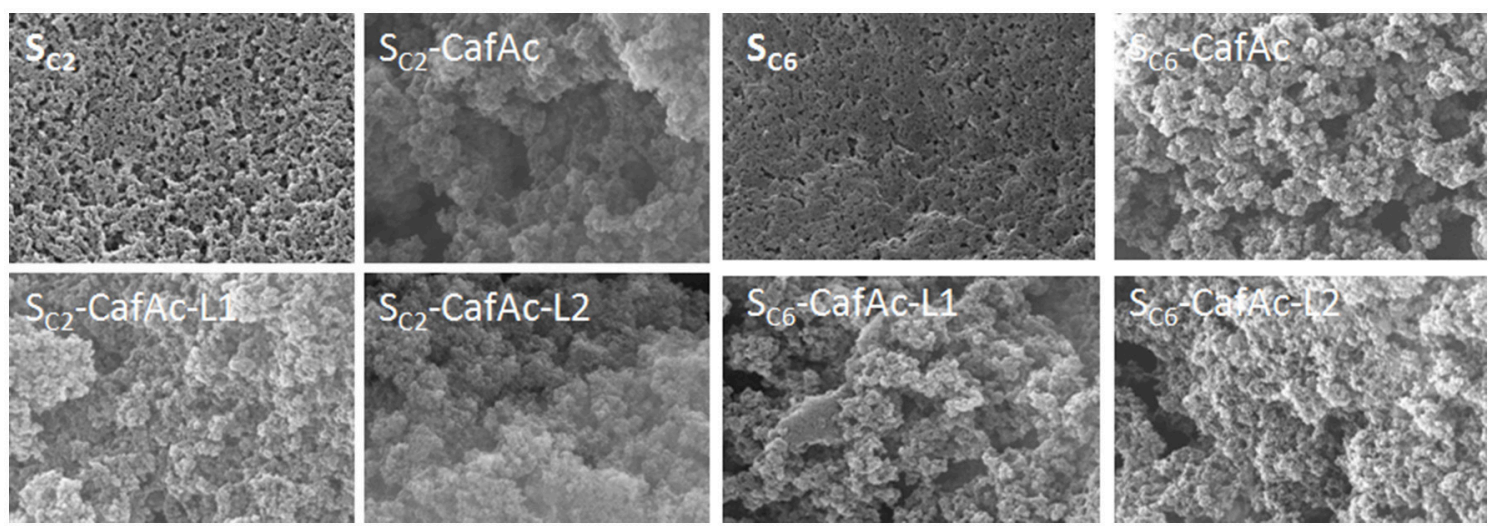

FIGURE 4 | SEM images of the particles with different composition: original particles (SC2 and SC6), CafAc-functionalized particles ( $\mathrm{S}_{\mathrm{C} 2} / \mathrm{S}_{\mathrm{C6}}$-CafAc), and bio-composites based on $\mathrm{CA}\left(\mathrm{S}_{\mathrm{C} 2} / \mathrm{S}_{\mathrm{C} 6}-\mathrm{CafAc}_{-} \mathrm{L}_{1}\right)$, and $\mathrm{SA}\left(\mathrm{S}_{\mathrm{C} 2} / \mathrm{S}_{\mathrm{C} 6}-\mathrm{CafAc}_{\mathrm{C}} \mathrm{L}_{2}\right)$ oxi-copolymerization. 


\section{CONCLUSIONS}

These results confirm the success of the one-pot approach for the production of lignin bio-composites via an enzyme oxi-copolymerization process. Monolignols such as SA and CA were easily attached on a support surface based on the interaction with immobilized CafAc leading to artificial lignin covering the support surface. SA allowed an advanced polymerization $\left(\mathrm{L}_{2}\right.$ polymer) and coverage compared to $\mathrm{CA}$ ( $\mathrm{L}_{1}$ polymer). Accordingly, $\mathrm{L}_{1}$-based bio-composites exhibited higher hydrophobicity than $\mathrm{L}_{2}$, while SA provided a more acidic bio-composite surface. Therefore, the developed protocol allows the synthesis of artificial lignin-based composites with predictable surface properties.

Based on these, the reported work offers a new alternative for the valorization of lignin residues with the production of new bio-composites following a green route. The versatility of the method may offer an easy control of the properties of the prepared bio-composites and an instrument to adjust them to different applications (e.g., support/ carrier for biomolecules).

\section{AUTHOR CONTRIBUTIONS}

All authors listed have made a substantial, direct and intellectual contribution to the work, and approved it for publication. SI and

\section{REFERENCES}

Aro, T., and Fatehi, P. (2017). Production and application of lignosulfonates and sulfonated lignin. ChemSusChem 10, 1861-1877. doi: 10.1002/cssc.201700082

Barzegari, M. R., Alemdar, A., Zhang, Y., and Rodrigue, D. (2013). Thermal analysis of highly filled composites of polystyrene with lignin. Polym. Polymer Composites 21, 357-366.

Brebu, M., Tamminen, T., and Spiridon, I. (2013). Thermal degradation of various lignins by TG-MS/FTIR and Py-GC-MS. J. Anal. Appl. Pyrolysis 104, 531-539. doi: 10.1016/j.jaap.2013.05.016

Brostow, W., Datashvili, T., Jiang, P., and Miller, H. (2016). Recycled HDPE reinforced with sol-gel silica modified wood sawdust. Eur. Polym. J. 76, 28-39. doi: 10.1016/j.eurpolymj.2016.01.015

Buono, P., Duval, A., Verge, P., Averous, L., and Habibi, Y. (2016). New insights on the chemical modification of Lignin: acetylation versus Silylation. ACS Sustain. Chem. Eng. 4, 5212-5222. doi: 10.1021/acssuschemeng.6b00903

Chung, Y. L., Olsson, J. V., Li, R. J., Frank, C. W., Waymouth, R. M., Billington, S. L., et al. (2013). A renewable lignin-lactide copolymer and application in biobased composites. ACS Sustain. Chem. Eng. 1, 1231-1238. doi: $10.1021 /$ sc4000835

Del Saz-Orozco, B., Oliet, M., Alonso, M. V., Rojo, E., and Rodríguez, F. (2012). Formulation optimization of unreinforced and lignin nanoparticle-reinforced phenolic foams using an analysis of variance approach. Compos. Sci. Technol. 72, 667-674. doi: 10.1016/j.compscitech.2012.01.013

Duta, L., Popescu, A. C., Dorcioman, G., Mihailescu, I. N., Stan, G. E., Zgura, I., et al. (2012). " $\mathrm{ZnO}$ thin films deposited on textile material substrates for biomedical applications: $\mathrm{ZnO}$ thin films deposited on textiles," in NATO Science for Peace and Security Series A: Chemistry and Biology, eds A. Vaseashta, E. Braman, and P. Susmann (Dordrecht: Springer), 207-210. doi: 10.1007/978-94-007-2488-4_20

Fitigău, I. F., Boeriu, C. G., and Peter, F. (2015). Enzymatic modification of different lignins through oxidative coupling with hydrophilic compounds. Macromol. Symp. 352, 78-86. doi: 10.1002/masy.201400157
$\mathrm{CO}$ performed the experiments for the preparation of the biocomposites and also UV-Vis/F-C analysis; BC performed TPD$\mathrm{NH} 3$ analysis; MT coordinated the research study and wrote the manuscript; IZ and AG characterized the bio-composites based on contact angle technique; $\mathrm{AB}$ performed FTIR analysis; $\mathrm{ME}$ and G-MM performed the SEM analysis and the interpretation of the corresponding results; VP revised and improved the manuscript.

\section{ACKNOWLEDGMENTS}

This work was financially supported by PN III TE program, contract no. 103/2015 and Core project PN-III-16-48-01 from MEN-UEFISCDI. We thank Purolite Life Sciences Company for Lifetech ECR8309F and Lifetech ECR8409F particles. Many thanks to dr. Miguel Alcalde (Institute of Catalysis, CSIC, Madrid, Spain) for 2-1B mutant of versatile peroxidase and dr. ing. Alexandru Branzan (Institute of Biology Bucharest of the Romanian Academy, Romania) for SEM analysis.

The authors are also grateful to the COST Action FP1306 for the financial support and transfer of knowledge.

\section{SUPPLEMENTARY MATERIAL}

The Supplementary Material for this article can be found online at: https://www.frontiersin.org/articles/10.3389/fchem. 2018.00124/full\#supplementary-material

Garcia-Ruiz, E., Gonzalez-Perez, D., Ruiz-Dueñas, F. J., Martínez, A. T., and Alcalde, M. (2012). Directed evolution of a temperature-, peroxideand alkaline pH-tolerant versatile peroxidase. Biochem. J. 441, 487-498. doi: 10.1042/BJ20111199

Gosselink, R. J. A., Abächerli, A., Semke, H., Malherbe, R., Käuper, P., Nadif, A., et al. (2004a). Analytical protocols for characterisation of sulphur-free lignin. Ind. Crops Prod. 19, 271-281. doi: 10.1016/j.indcrop.2003.10.008

Gosselink, R. J. A., de Jong, E., Guran, B., and Abächerli, A. (2004b). Co-ordination network for lignin-standardisation, production and applications adapted to market requirements (EUROLIGNIN). Ind. Crops Prod. 20, 121-129. doi: 10.1016/j.indcrop.2004.04.015

Hao, D. C., Gu, X.-J., and Xiao, P. G. (eds.). (2015). "14 Phytochemical and biological research of Salvia medicinal resources," in Medicinal Plants (Cambridge: Woodhead Publishing), 587-639. doi: 10.1016/B978-0-08-100085-4.00001-3

Hu, L., Pan, H., Zhou, Y., and Zhang, M. (2011). Methods to improve lignin's reactivity as a phenol substitute and as replacement for other phenolic compounds: a brief review. Bioresources 6, 3515-3525.

Kramárová, Z., Alexy, P., Chodák, I., Špirk, E., Hudec, I., Košíková, B., et al. (2007). Biopolymers as fillers for rubber blends. Polym. Adv. Technol. 18, 135-140. doi: $10.1002 /$ pat.803

Lee, J. H., and Wendisch, V. F. (2017). Biotechnological production of aromatic compounds of the extended shikimate pathway from renewable biomass. J. Biotechnol. 257, 211-221. doi: 10.1016/j.jbiotec.2016.11.016

Lee, R. A., Bédard, C., Berberi, V., Beauchet, R., and Lavoie, J. M. (2013). UV-Vis as quantification tool for solubilized lignin following a single-shot steam process. Bioresour. Technol. 144(Suppl. C), 658-663. doi: 10.1016/j.biortech.2013.06.045

Lora, J. H., and Glasser, W. G. (2002). Recent industrial applications of lignin: a sustainable alternative to nonrenewable materials. J. Polym. Environ. 10, 39-48. doi: 10.1023/A:1021070006895

Luo, X., Mohanty, A., and Misra, M. (2013). Lignin as a reactive reinforcing filler for water-blown rigid biofoam composites from soy oil-based polyurethane. Ind. Crops Prod. 47, 13-19. doi: 10.1016/j.indcrop.2013.01.040 
Molina-Espeja, P., Garcia-Ruiz, E., Gonzalez-Perez, D., Ullrich, R., Hofrichter, M., and Alcalde, M. (2014). Directed evolution of unspecific peroxygenase from Agrocybe aegerita. Appl. Environ. Microbiol. 80, 3496-3507. doi: 10.1128/AEM.00490-14

Molina-Espeja, P., Ma, S., Mate, D. M., Ludwig, R., and Alcalde, M. (2015). Tandem-yeast expression system for engineering and producing unspecific peroxygenase. Enzyme Microb. Technol. 73-74, 29-33. doi: 10.1016/j.enzmictec.2015.03.004

Morandim-Giannetti, A. A., Agnelli, J. A. M., Lanças, B. Z., Magnabosco, R., Casarin, S. A., and Bettini, S. H. P. (2012). Lignin as additive in polypropylene/coir composites: thermal, mechanical and morphological properties. Carbohydr. Polym. 87, 2563-2568. doi: 10.1016/j.carbpol.2011.11.041

Nair, S. S., Sharma, S., Pu, Y., Sun, Q., Pan, S., Zhu, J. Y., et al. (2014). High shear homogenization of lignin to nanolignin and thermal stability of nanolignin-polyvinyl alcohol blends. ChemSusChem 7, 3513-3520. doi: $10.1002 /$ cssc. 201402314

Opris, C., Amanov, N., Parvulescu, V. I., and Tudorache, M. (2018). Peroxidasebased oxidative polymerization of monolignols. Comp. Rendus Chim. 21, 362-368. doi: 10.1016/j.crci.2017.09.002

Opris, C., Cojocaru, B., Gheorghe, N., Tudorache, M., Coman, S. M., Parvulescu, V. I., et al. (2016). Lignin fragmentation over magnetically

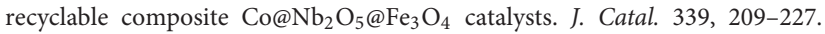
doi: $10.1016 /$ j.jcat.2016.04.002

Opris, C., Cojocaru, B., Gheorghe, N., Tudorache, M., Coman, S. M., Parvulescu, V. I., et al. (2017). Lignin fragmentation onto multifunctional $\mathrm{Fe}_{3} \mathrm{O}_{4} @ \mathrm{Nb}_{2} \mathrm{O}_{5} @ \mathrm{Co} @ \mathrm{Re}$ catalysts: the role of the composition and deposition route of rhenium. ACS Catal. 7, 3257-3267. doi: 10.1021/acscatal.6b02915

Poletto, M., and Zattera, A. J. (2013). Materials produced from plant biomass: part III: degradation kinetics and hydrogen bonding in lignin. Mater. Res. 16, 1065-1070. doi: 10.1590/S1516-14392013005000112

Popescu, A. C., Duta, L., Dorcioman, G., Mihailescu, I. N., Stan, G. E., Pasuk, I., et al. (2011). Radical modification of the wetting behavior of textiles coated with $\mathrm{ZnO}$ thin films and nanoparticles when changing the ambient pressure in the pulsed laser deposition process. J. Appl. Phys. 110:064321. doi: $10.1063 / 1.3639297$

Preda, N., Enculescu, M., Zgura, I., Socol, M., Matei, E., Vasilache, V., et al. (2013). Superhydrophobic properties of cotton fabrics functionalized with $\mathrm{ZnO}$ by electroless deposition. Mater. Chem. Phys. 138, 253-261. doi: 10.1016/j.matchemphys.2012.11.054

Pucciariello, R., Villani, V., Bonini, C., D’Auria, M., and Vetere, T. (2004). Physical properties of straw lignin-based polymer blends. Polymer 45, 4159-4169. doi: 10.1016/j.polymer.2004.03.098

Pupure, L., Varna, J., Joffe, R., and Pupurs, A. (2013). An analysis of the nonlinear behavior of lignin-based flax composites. Mech. Composite Mater. 49, 139-154. doi: 10.1007/s11029-013-9330-x

Qian, Y., Deng, Y., Qiu, X., Li, H., and Yang, D. (2014). Formation of uniform colloidal spheres from lignin, a renewable resource recovered from pulping spent liquor. Green Chem. 16, 2156-2163. doi: 10.1039/c3gc42131g

Qu, Y., Luo, H., Li, H., and Xu, J. (2015). Comparison on structural modification of industrial lignin by wet ball milling and ionic liquid pretreatment. Biotechnol. Rep. 6(Suppl. C), 1-7. doi: 10.1016/j.btre.2014.12.011

Salanti, A., Zoia, L., Zanini, S., and Orlandi, M. (2016). Synthesis and characterization of lignin-silicone hybrid polymers as possible consolidants for decayed wood. Wood Sci. Technol. 50, 117-134. doi: 10.1007/s00226-015-0772-2

Setua, D. K., Shukla, M. K., Nigam, V., Singh, H., and Mathur, G. N. (2000). Lignin reinforced rubber composites. Polymer Composites 21, 988-995. doi: $10.1002 / p c .10252$

Singleton, V. L., Orthofer, R., and Lamuela-Raventos, R. M. (1999). Analysis of total phenols and other oxidation substrates and antioxidants by means of Folin-Ciocalteu Reagent. Methods Enzymol. 299, 152-178. doi: 10.1016/S0076-6879(99)99017-1
Stanzione, J. F. III., Giangiulio, P. A., Sadler, J. M., La Scala, J. J., and Wool, R. P. (2013). Lignin-based bio-oil mimic as biobased resin for composite applications. ACS Sustain. Chem. Eng. 1, 419-426. doi: 10.1021/sc3001492

Stewart, D. (2008). Lignin as a base material for materials applications: chemistry, application and economics. Ind. Crops Prod. 27, 202-207. doi: 10.1016/j.indcrop.2007. 07.008

Strzemiecka, B., Klapiszewski, Ł., Jamrozik, A., Szalaty, T. J., Matykiewicz, D., Sterzynski, T., et al. (2016). Physicochemical characterization of functional lignin-silica hybrid fillers for potential application in abrasive tools. Materials 9:E517. doi: 10.3390/ma9070517

Thakur, V. K., Thakur, M. K., Raghavan, P., and Kessler, M. R. (2014). Progress in green polymer composites from lignin for multifunctional applications: a review. ACS Sustain. Chem. Eng. 2, 1072-1092. doi: 10.1021/sc50 $0087 \mathrm{z}$

Thanh Binh, N. T., Luong, N. D., Kim, D. O., Lee, S. H., Kim, B. J., Lee, Y. S., et al. (2009). Synthesis of lignin-based thermoplastic copolyester using kraft lignin as a macromonomer. Composite Interfaces 16, 923-935. doi: 10.1163/092764409X12477479344485

Thomas, A., Allouche, M., Basyn, F., Brasseur, R., and Kerfelec, B. (2005). Role of the lid hydrophobicity pattern in pancreatic lipase activity. J. Biol. Chem. 280, 40074-40083. doi: 10.1074/jbc.M502123200

Vinardell, M. P., Ugartondo, V., and Mitjans, M. (2008). Potential applications of antioxidant lignins from different sources. Ind. Crops Prod. 27, 220-223. doi: 10.1016/j.indcrop.2007.07.011

Xiong, W., Yang, D., Zhong, R., Li, Y., Zhou, H., and Qiu, X. (2015). Preparation of lignin-based silica composite submicron particles from alkali lignin and sodium silicate in aqueous solution using a direct precipitation method. Ind. Crops Prod. 74, 285-292. doi: 10.1016/j.indcrop.2015. 05.021

Yamamoto, Y., Shirono, H., Kono, K., and Ohashi, Y. (1997). Immunopotentiating activity of the water-soluble lignin rich fraction prepared from lem-the extract of the solid culture medium of Lentinus edodes mycelia Biosci. Biotechnol. Biochem. 61, 1909-1912. doi: 10.1271/bbb.61.1909

Yin, Q., Yang, W., Sun, C., and Di, M. (2012). Preparation and properties of lignin-epoxy resin composite. Bioresources 7, 5737-5748. doi: 10.15376/biores.7.4.5737-5748

Zakzeski, J., Bruijnincx, P. C., Jongerius, A. L., and Weckhuysen, B. M. (2010). The Catalytic valorization of lignin for the production of renewable chemicals. Chem. Rev. 110, 3552-3599. doi: 10.1021/cr900354u

Zgura, I., Beica, T., Mitrofan, I. L., Mateias, C. G., Pirvu, D., and Patrascu, I. (2010). Assessment of the impression materials by investigation of the hydrophilicity. Digest. J. Nanomat. Biostruct. 5, 749-755.

Zgura, I., Moldovan, R., Negrila, C. C., Frunza, S., Cotorobai, V. F., and Frunza, L. (2013). Surface free energy of smooth and dehydroxylated fused quartz from contact angle measurements using some particular organics as probe liquids. J. Optoelectron. Adv. Mater. 15, 627-634.

Zou, H., Wu, S., and Shen, J. (2008). Polymer/silica nanocomposites: preparation, characterization, propertles, and applications. Chem. Rev. 108, 3893-3957. doi: $10.1021 /$ cr068035q

Conflict of Interest Statement: The authors declare that the research was conducted in the absence of any commercial or financial relationships that could be construed as a potential conflict of interest.

Copyright $\odot 2018$ Ion, Opris, Cojocaru, Tudorache, Zgura, Galca, Bodescu, Enache, Maria and Parvulescu. This is an open-access article distributed under the terms of the Creative Commons Attribution License (CC BY). The use, distribution or reproduction in other forums is permitted, provided the original author(s) and the copyright owner are credited and that the original publication in this journal is cited, in accordance with accepted academic practice. No use, distribution or reproduction is permitted which does not comply with these terms. 